\title{
THE ROLE OF COPPER STAVES IN ACHIEVING EFFICIENT OPERATION AND LONG BLAST FURNACE CAMPAIGN LIFETIME*
}

\author{
Jean-Paul Simoes ${ }^{1}$ \\ Paul Goedert ${ }^{2}$ \\ Christian de Gruiter ${ }^{3}$ \\ Nicolas Maggiolit \\ Cristiano Castagnola ${ }^{5}$
}

\begin{abstract}
The development of the blast furnace over the last years lead to a substantial increase in production capacity and productivity. This development triggered an evolution of the cooling systems in order to cope with the raising heat loads. The excellent protection of the shell by copper staves allowed blast furnace operators to achieve campaign lifetimes of more than 20 years. However in recent years some blast furnaces have experienced severe wear of the copper staves due to abrasion. The influences of the blast furnace design as well as of the operation conditions on this premature wear have been analysed and the mechanisms leading to the wear will be explained. New developments in the copper stave technology are part of the solution for avoiding premature wear during periods with less favourable conditions. The protection mechanisms made available by the new design extend the inherent protection mechanisms of copper staves to these periods. BFXpert@ system is the ideal tool for the monitoring of the process data, the process models and the recommendations given by Sachem ${ }^{\circledR}$ support the operator in choosing efficient operation points. The charging with a Bell Less Top® (BLT) allows an accurate controlling of the blast furnace with regard to the optimization of the gas distribution.

High performance operation together with long campaign lifetimes are thus made possible.
\end{abstract}

Keywords: Blast furnace; Copper staves; Bell less top; Expert system.

1 Metallurgy, PhD, Head of Section, BF Plant \& Process, Paul Wurth S.A., Luxembourg, Luxembourg.

2 Physics, Master, Senior Project Engineer, BF Process \& Technology, Paul Wurth S.A., Luxembourg, Luxembourg.

3 Mechanical Eng., M.Sc., Senior Project Engineer, CTM R\&D Mechanics, Paul Wurth S.A., Luxembourg, Luxembourg.

4 Mechanical Eng., M.Sc., Senior Project Engineer, BF Process \& Technology, Paul Wurth S.A., Luxembourg, Luxembourg.

5 Chemical Eng., M.Sc., General Manager Engineering, Blast Furnace, Paul Wurth S.P.A., Genova, Italy.

\footnotetext{
* Technical contribution to the $44^{\text {th }}$ Ironmaking and Raw Materials Seminar, $15^{\text {rd }}$ Brazilian Symposium on Iron Ore and $2^{\text {nd }}$ Brazilian Symposium on Agglomeration of Iron Ore, September $15^{\text {th }}$ to $18^{\text {th }}$, 2014, Belo Horizonte, MG, Brazil.
} 


\section{INTRODUCTION}

The increases in productivity and availability of blast furnaces achieved during the last decades have on one hand allowed reducing the hot metal production costs and on the other hand increased the intensity of the process leading to an increase of the required heat removal capacity of the cooling systems. The provisional end of this development is the cooling system based on copper staves. In recent years however this success story experienced some headwind from cases of severe premature wear by abrasion of copper staves experienced by several blast furnace operators. The operation conditions leading to this wear have been analyzed, the wear mechanisms have been identified and solutions to improve the copper stave hot face wear resistance have been developed.

\section{BF COOLING SYSTEMS}

\subsection{Historic Review}

The main aim of all the developments around the blast furnace cooling systems was the protection of the shell and thus the extension of the blast furnaces' campaign life. The first blast furnace water cooling circuits appearing in 1884 have been applied to the hearth and bosh area, and later, in the 1930's, extended to the stack area.

The earlier cooling methods relied on an outer cooling of the shell by spray and surface water irrigation, later for a more effective protection of the shell the cooling has been relocated inside the blast furnace. For improving the cooling, plate coolers reaching through the shell into the lining have been added to the spray cooling.

The development of copper cooling plates/boxes lead to an abandon of outer cooling methods. In order to cope with the still too high heat fluxes to the shell after the loss of the lining between the plates, the density of the plates has been increased in the high heat load zones of the belly and lower stack. The large number of openings required for their installation required compensation in shell thickness and quality as well as much longer installation and lining time, thus higher investment and longer stoppages.

The main advantage of the cast iron stave technology initially developed in the late fifties in Russia, if compared to the cooling plates, is the complete protection of the blast furnace shell and thus the increased lifetime of the shell. The increasing blast furnaces size and productivity as well as the upcoming injection of reducing agents, lead to a further increase of the heat fluxes in the belly and lower stack region which could no more be handled by the limited heat removal capacity of cast iron staves. This lead to the development of the copper staves in the late seventies.

\subsection{The Basic Principle of the Copper Stave Technology}

The idea to use copper staves in the blast furnace, was to combine the complete protection of a stave cooling solution with the advantages offered by the copper material.

The main advantage of the copper stave, the higher heat flux removal capacity if compared to the cast iron stave can be explained by the following aspects:

- $\quad$ the ten times higher thermal conductivity of copper

- $\quad$ the direct contact between the stave body and the water resulting from the fact that the channels are directly casted or drilled into the copper stave body.

\footnotetext{
* Technical contribution to the $44^{\text {th }}$ Ironmaking and Raw Materials Seminar, $15^{\text {rd }}$ Brazilian Symposium on Iron Ore and $2^{\text {nd }}$ Brazilian Symposium on Agglomeration of Iron Ore, September $15^{\text {th }}$ to $18^{\text {th }}$, 2014, Belo Horizonte, MG, Brazil.
} 
The high heat flux removal capacity facilitates the build-up of an accretion layer and the hot face temperatures are lower than for the cast iron staves. Any liquid, or partially liquefied, material will, due to the high heat loss when in contact with the stave surface, immediately solidify on the naked stave hot surface. The resulting protective layer will have two major benefic aspects:

- $\quad$ Thermal insulation of the stave; indeed with the accretion layer the heat loss of the copper staves become lower than for a cast iron stave in the same location

- Protection of the rather soft copper surface against wear.

Due to the sliding of the burden on the wall, the accretion layer on the staves may be lost from time to time, resulting in a sudden increase of the copper stave body temperature up to $120-130^{\circ} \mathrm{C}$. These stave body peak temperatures are still rather low if compared to the admissible maximum temperature for copper of $500^{\circ} \mathrm{C}$ and the body peak temperatures up to $900^{\circ} \mathrm{C}$ recorded in cast iron staves [1]. After a loss of the accretion layer, a new accretion layer will build-up immediately. The protective layer formation time being quite short guarantees that the protective layer is in place most of the time so that the heat losses are reduced at a maximum and the stave permanently is well protected against mechanical abrasion.

However the build-up of an accretion layer can only take place if there is molten or at least partly molten material available at the stave hot surface. Raw materials well "prepared" in the upper part of the blast furnace melt early and protect as much copper stave surface as possible. A good burden preparation in the wall area can only be achieved by a high specific gas flow rate at the wall requesting a highly permeable material mix at the wall.

BF 6 of NTMK in Russia was the first blast furnace with evaporative cooling system to be equipped with copper staves in 2004 [2]. Operation experience has shown that even with a working volume productivity of up to $3.3 \mathrm{t} /\left(\mathrm{m}^{3} \mathrm{~d}\right)$ the same stave selfprotecting mechanisms as with conventional forced circulation cooling systems are taking place. No damages to the staves have been noticed during 9 years of operation.

For BF reline projects the replacement of copper cooling plates by copper staves has the advantage of increasing the working volume and thus the production capacity of the blast furnace. Furthermore the required relining time is considerably reduced as setting the lining in between the copper cooling plates is no longer necessary.

\subsection{Premature Wear of Copper Staves}

The experience of premature wear of copper staves has shown that the above described mechanism of stave protection by a protective accretion layer does not always take place as required. In order to highlight the reasons leading to premature copper wear, the factors influencing the abrasive wear (Figure 1) have to be studied in detail.

Copper staves, without inserts, removed from blast furnaces after 15 years and more of operation, showing almost no wear, demonstrate that the self-protection mechanism of the copper staves protects them effectively against the descending burden. In some cases the copper staves remain in the blast furnace for more than one campaign. The request for longer campaigns was actually the starting point for the development of copper staves. As the build-up of the accretion layer is only possible below or in the cohesive zone, the roots of the cohesive zone should be located as high as possible so that the surface of copper staves located in the safe area is maximized.

\footnotetext{
* Technical contribution to the $44^{\text {th }}$ Ironmaking and Raw Materials Seminar, $15^{\text {rd }}$ Brazilian Symposium on Iron Ore and $2^{\text {nd }}$ Brazilian Symposium on Agglomeration of Iron Ore, September $15^{\text {th }}$ to $18^{\text {th }}$, 2014, Belo Horizonte, MG, Brazil.
} 

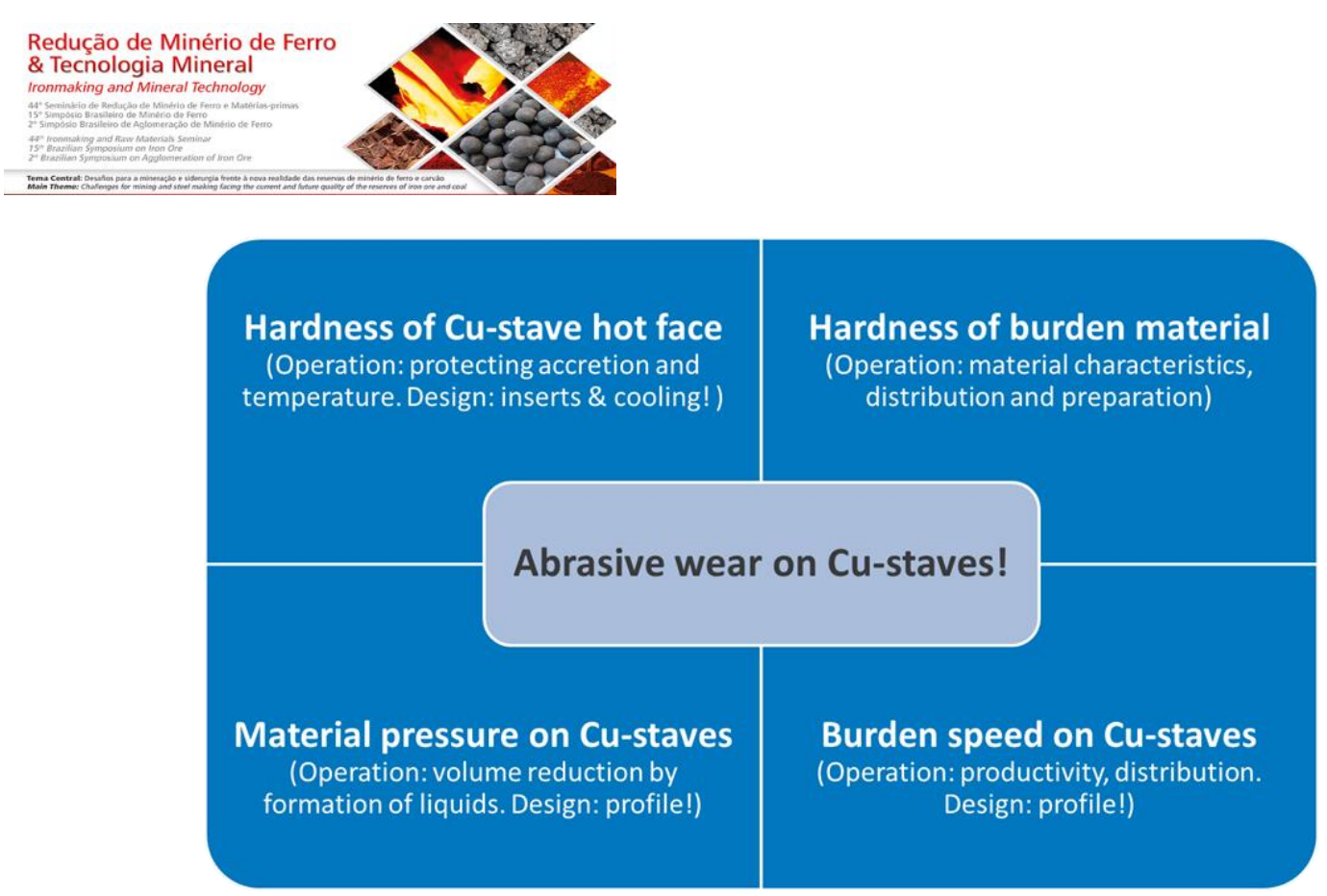

Figure 1. : Factors influencing copper stave wear.

It has to be noticed that this requirement leads to an operation philosophy completely different from the one used with cast iron staves. In order to protect cast iron staves from the high heat flows present in the belly and lower stack region, operators try to limit the gas flow at the wall by charging materials with low permeability at the wall and by opening the center. Especially blast furnace operators having a long time experience with cast iron staves and switching to a cooling with copper staves have to get aware of this required change in operation philosophy.

The hardness of the burden materials interacting with the copper stave hot surface affects the wear behavior. The harder the burden components, the higher will be the abrasion effect on the stave. The hardness of the burden will decrease with higher temperature and with the reduction degree of the ferrous materials. The surface structure of the burden material, the chemical composition and the mix of materials also influence the wear behavior. Sharp edged grains have a higher wearing potential than more spherical grains.

Tests have shown that unreduced sinter is twice as much hard as reduced sinter. Unreduced pellets are even three times as hard as reduced pellets. Due to the spherical form of the pellets they are however less abrasive than sinter.

Coke has approximately the same hardness as sinter but is also less abrasive due to its surface shape. Blast furnaces equipped with copper staves and operating at coke rates of $600 \mathrm{~kg} / \mathrm{tHm}$ with no center coke have shown no wear of the copper staves so that no major role can be attributed to the coke in the wear mechanisms of the copper staves.

The evidence of poorly reduced material at the wall area in the bosh is given by several key-indicators. These have been implemented and are monitored by Paul Wurth's BFXpert® Level-2 System. A sampling opening per stave row allowing taking ferrous burden samples along the shaft height in order to be able to analyze the reduction degree as well as the burden consistency.

The normal force on the wall results from the given blast furnace profile and the operation conditions. Solid flow modelling shows pressure peaks of the normal force on the wall just below the junction between the shaft and the belly as well at the junction between the belly and the bosh.

\footnotetext{
* Technical contribution to the $44^{\text {th }}$ Ironmaking and Raw Materials Seminar, $15^{\text {rd }}$ Brazilian Symposium on Iron Ore and $2^{\text {nd }}$ Brazilian Symposium on Agglomeration of Iron Ore, September $15^{\text {th }}$ to $18^{\text {th }}$, 2014, Belo Horizonte, MG, Brazil.
} 
The convergent conical downward shape of the bosh accounts for the volume reduction of the burden material due to the melt down. A blast furnace operation leading to the material melting lower in the blast furnace and thus increasing the material volume in the bosh leads to an increase of the material pressure on the wall. The burden descend speed at the wall area is conditioned by three factors; the productivity, the profile as well as the material and gas distribution.

A higher productivity will lead to more burden material passing through a given section of the blast furnace per unit of time and so lead to an increased burden descend velocity at the wall. High productivity often coincides with high injection rate and high oxygen enrichment, thus the counter-current average gas to material flow ratio is reduced, making a good material "preparation" at the peripheral area more important. Due to the consumption of coke in the raceway in front of the tuyeres, the highest material velocities are found just above the raceways. High velocity areas are prone to higher abrasion. A low shaft angle can reduce the abrasion in this region. The resulting larger belly will promote the formation of a stagnant zone at the wall and thus minimize the velocity of the material at the wall. The same is valid for the bosh angle. A low angle will be favorable to the formation of a stagnant zone.

Paul Wurth has extensive knowledge on blast furnace inner profiles. As in the recent years the main aim was to maximize the inner furnace volume, in some cases, the importance of the profile has been neglected.

Theburden and gas distribution have an important role on the liquefaction of ferrous material and thus on the burden speed at the wall area in the lower blast furnace. Modern charging equipment such as Paul Wurth's Bell Less Top® (BLT®) and the level-2 automation systems such as BFXpert® are the ideal tools to optimize the burden/gas distribution to all operating conditions and achieve best performance in terms of fuel rate, productivity and hot metal quality as well as campaign lifetime.

\section{HIGH PERFORMANCE OPERATION WITH COPPER STAVES}

\subsection{Operational Support}

Today's market imposes a higher degree of flexibility to blast furnace process in terms of raw materials and operating conditions. In order to achieve always a high level of performance and long campaigns, first a consistent design and instrumentation as well as in-depth process knowledge and process control are required. The copper staves protecting the blast furnace shell in an optimum way, support the operation with high performance under changing raw material and operation conditions.

As the control of the gas flow at the wall is a key factor for avoiding wear and that the gas distribution in the blast furnace can be best controlled by the charging, the use of optimized charging equipment is a key advantage in achieving this goal.

The development of the Bell Less Top improved the flexibility and accuracy of burden distribution compared to older type double bell top charging systems. The Bell Less Top guarantees a homogenous distribution of the burden around the blast furnace throat. The Central Feed Bell Less Top for small to medium size furnaces is the ideal solution for providing a highly accurate centered material stream on the distribution chute, thus guaranteeing circular burden rings. Along with the Central Feed Bell Less Top, the second generation 2-Hopper and 3-Hopper Bell Less Top provide a centered material stream (Figure 2).

\footnotetext{
* Technical contribution to the $44^{\text {th }}$ Ironmaking and Raw Materials Seminar, $15^{\text {rd }}$ Brazilian Symposium on Iron Ore and $2^{\text {nd }}$ Brazilian Symposium on Agglomeration of Iron Ore, September $15^{\text {th }}$ to $18^{\text {th }}$, 2014, Belo Horizonte, MG, Brazil.
} 

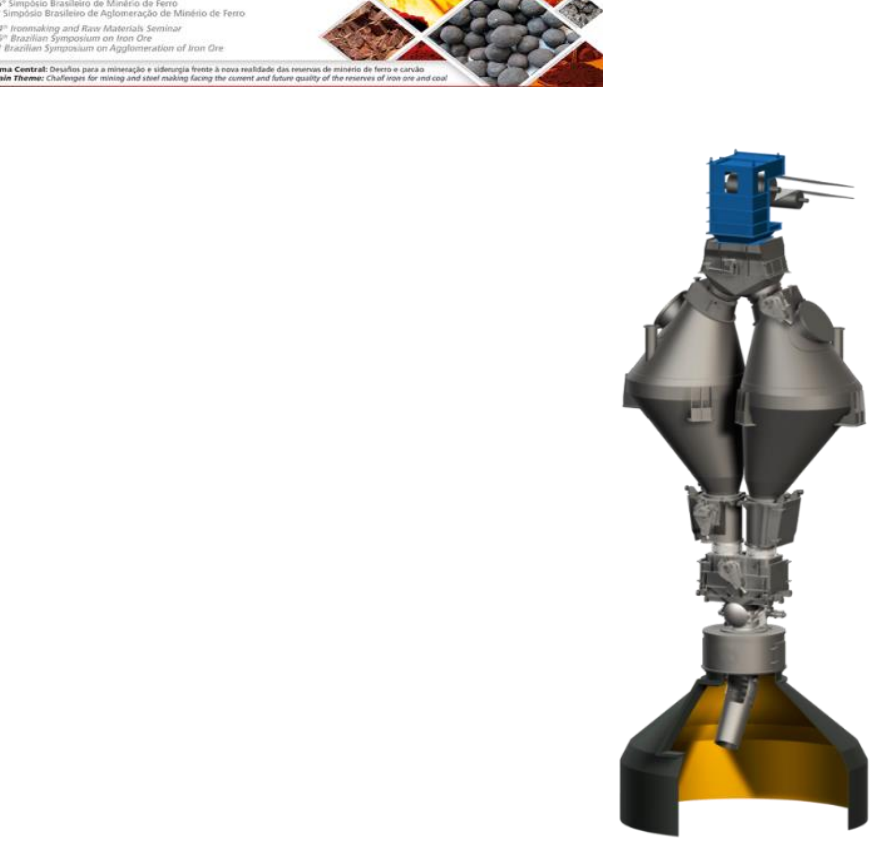

Figure 2 : Modern 2nd generation 2-Hopper Bell Less Top (with G3 chute transmission gearbox).

The burden flow rate must remain constant throughout the material hopper discharge to ensure that the material layer thickness is constant and that burden rings are closed. The control and setting of the burden flow rate is done via a self-correcting algorithm correlating the target burden discharge rate to the material gate opening angle for each hopper and each burden composition [3].

Today the most common way to manage the gas flow at the wall is to control burden distribution, understanding that the Ore to Coke and size distribution ratio along the blast furnace throat radius is a reasonable indicator of the gas distribution. The amount of coke at the wall can be precisely controlled in order to ensure the proper heating and reduction of iron ore bearing materials. A lack of coke inevitably leads to unreduced burden materials descending through the shaft. In severe cases this can result in unreduced material as low as the bosh or tuyere level. In case of advanced stock house facilities, fines may be charged separately at mid-radius in order to keep a sufficient flow of gas in the wall region without compromising the permeability of the center chimney.

All the parameters in relation with the health status of the charging equipment are best monitored by means of the newly developed Condition Monitoring system [4], which is ideally integrated in the complete BFXpert system described here below.

It is generally recognized that the blast furnace operation can benefit from the use of level-2 automation and expert systems. Despite their main task of ensuring a cost optimized production, thus a low fuel rate, there is a significant benefit on the equipment lifetime. This benefit is the result first from bringing the blast furnace to good operation conditions favorable for the equipment lifetime and second from avoiding incidents which might have a major impact on the state of the equipment.

The level-2 system BFXpert consists of a modular set of integrated powerful on-line and off-line process models on a common platform including SACHEM ${ }^{\circledR}$ expert system as well as BFXpert RULES and other tools. BFXpert covers all main areas of blast furnace iron making such as charging, blast and injection, tapping and supervision. It provides diagnostics as well as recommendations to assist blast furnace managers, process engineers and operators as well as maintenance staff in their daily tasks to safely achieve the target production at optimized cost as well as ensuring a longer campaign life [5].

\footnotetext{
* Technical contribution to the 44 Ironmaking and Raw Materials Seminar, $15^{\text {rd }}$ Brazilian Symposium on Iron Ore and $2^{\text {nd }}$ Brazilian Symposium on Agglomeration of Iron Ore, September $15^{\text {th }}$ to $18^{\text {th }}$, 2014, Belo Horizonte, MG, Brazil.
} 
The Burdening Interface model, also known as BURD-IB, integrates several important steps required for charging. First, a mass balance tool helps technicians with calculations required to determine raw material and flux rates for a given burden composition, while accounting for slag basicity, $\mathrm{MgO}$ target and coke/ferrous base targets. Next, the stock-house matrix is set; in which the filling sequence of the main conveyor or skips is defined, choosing the appropriate stock-house material bins, with integrated checks that limit the risk of error. A third critical step results in creation of the Bell Less Top matrix, directly impacting the charging pattern [3].

A coupling between BURD-I and the Charging Model permits an easy assessment of the resultant matrix and its effect on the charging pattern and thus reduces greatly the number of iterative steps required to optimize the charging matrix. The Charging Model provides visualization of burden layer pile-up, coke push effect, ore to coke ratio calculations across the blast furnace radius, and an estimation of the cohesive zone (See Figure 3). This detailed information gives users the possibility to evaluate the quality of a charging matrix not only in terms of process but also in regard to their impact on the cooling equipment.

The cooling equipment is monitored by the BFXpert model "thermal status", which provides a heat load diagram of the furnace. The monitoring of the thermal status of the staves in function of their location allows the detection of the thermal conditions in the wall area and thus the early detection of non-optimum burden preparation conditions at the wall. Together with the measurement of skin flow temperatures, a risk factor for premature wear of the copper staves is calculated.

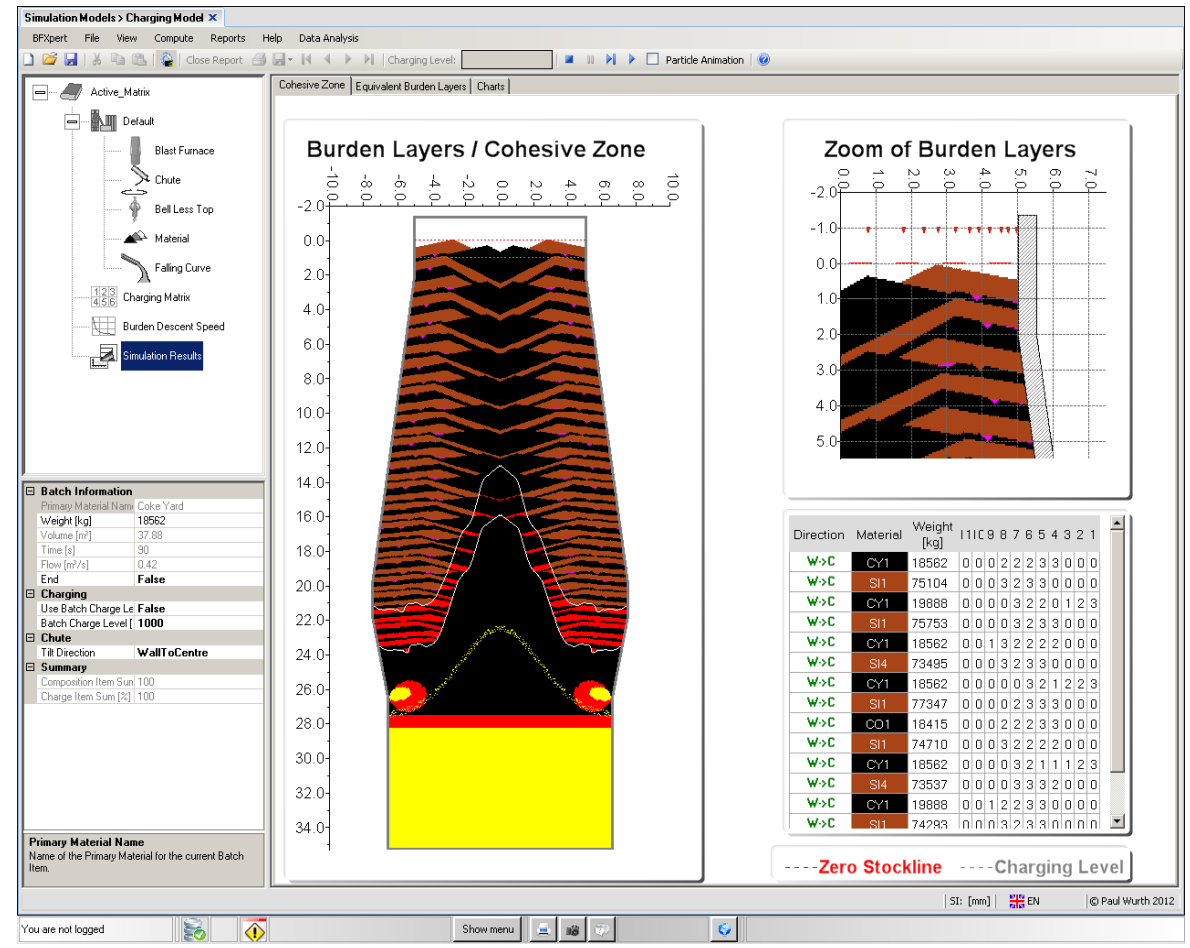

Figure 3. : BFXpert, View of the Charging Model

In the lower part of the blast furnace the Raceway Model provides the information about gas amount, composition and temperature as well as its penetration depth. The raceway adiabatic flame temperature has a direct influence on the position of the roots of the cohesive zone and the raceway depth influences the gas distribution in the furnace and thus the position and the shape of the cohesive zone. The close

\footnotetext{
* Technical contribution to the $44^{\text {th }}$ Ironmaking and Raw Materials Seminar, $15^{\text {rd }}$ Brazilian Symposium on Iron Ore and $2^{\text {nd }}$ Brazilian Symposium on Agglomeration of Iron Ore, September $15^{\text {th }}$ to $18^{\text {th }}$, 2014, Belo Horizonte, MG, Brazil.
} 
monitoring of these parameters made possible by the Raceway Model allows stabilizing the position and the shape of the cohesive zone in a way to guarantee a good preparation of the materials at the wall and thus to optimize the performance of the BF.

The SACHEM expert system constantly analyses the information coming from the process, informs the user about any deviations from the optimal operation conditions and provides recommendations to stabilize the furnace operation.

Based on the above analysis of the factors influencing the wear, favorable operation conditions leading to high performance without wear can be derived.

A good preparation of the material at the wall supports high productivity and is the starting point for avoiding premature wear on the copper staves. A good preparation means that the materials at the wall are heated early after charging so that already temperatures of about $300^{\circ} \mathrm{C}$ are reached at a level of $5 \mathrm{~m}$ below the burden surface. When the materials come into the lower part of the shaft where the copper staves are installed, the material should already be softer due to the higher temperature and a partial reduction. The good preparation of the materials at the wall will lead to a quite high location of the roots of the cohesive zone so that staves in the bosh and the belly are well protected by an accretion layer. A good burden preparation at the wall can only be achieved by an adequate specific gas flow rate at the wall which highlights the primordial importance of accurate burden distribution equipment.

The modern charging system in combination with the process models from BFXpert provide a valuable support to the operator to operate the blast furnace with high productivity while achieving long campaign lifetimes.

\subsection{New Technologies}

As possible premature stave wear of copper staves was only visible after blowing down the burden at a blast furnace shut-down, it became necessary to develop a measurement system allowing measuring the stave wear on regular intervals during normal operation. As complementary inspection holes only provide spot measurements, Paul Wurth developed an ultrasonic based thickness measurement. A copper rod is installed through the shell, the backfilling and the stave body. During installation the rod is cut in a way that its section surface in the blast furnace is flushed with the current hot face of the stave, so that the stave wear already existing at the moment of installation is taken into account. As the rods are made of a similar copper grade than the stave body, they will wear at the same rate than the copper stave bodies at the given location. The measurement of the remaining length of the rod is done by means of a pulse-echo ultrasonic thickness gauge. The thickness measurement can be done during blast furnace operation without dismantling the rods. In such a way, with regular measurement, a pattern of the wear over time can be drawn and will allow the identification of high wear periods. This allows analyzing the operation conditions during the high wear period in order to determine the reasons and to avoid the same adverse conditions in the future.

The experience made in recent years has shown that adverse operation conditions resulting in wear of copper staves may not always be avoided. In order to protect the equipment during such periods, Paul Wurth has developed new stave concepts.

The premature wear patterns experienced at different blast furnaces showed the existence of areas with higher wear than for the rest of the stave. Such a high wear area is noticed in the middle of the top part of the staves. It is due to the balcony effect. The installation of flat staves in a curved shell will lead to the formation of an

\footnotetext{
* Technical contribution to the 44 Ironmaking and Raw Materials Seminar, $15^{\text {rd }}$ Brazilian Symposium on Iron Ore and $2^{\text {nd }}$ Brazilian Symposium on Agglomeration of Iron Ore, September $15^{\text {th }}$ to $18^{\text {th }}$, 2014, Belo Horizonte, MG, Brazil.
} 
angle between two adjacent stave hot surfaces. It is usual to have an offset of half a stave width from one row to the next. Thus the middle top part of the stave of the lower row will be protruding as a "balcony" into the blast furnace in the edge formed by the two staves installed in the row above and will be subject to higher wear. The curved profile of the new generation staves fits exactly to the radius of the blast furnace profile and avoids the formation of balconies.

The temperature difference between the cold and the hot face leads to thermal stress inside the stave body. As the plasticity limit is surpassed on different locations inside

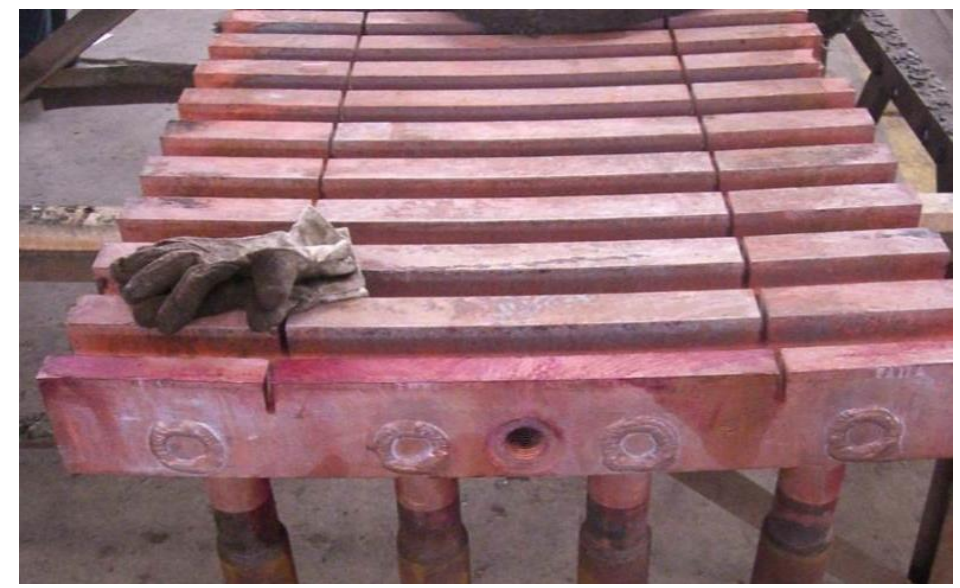

Figure 4. : Stave with Slicing

the stave body, the edges of the staves tend to bend inside the blast furnace after a few temperature cycles at the hot face. The bending leads to a protrusion of the edges of the staves inside the furnace. These exposed areas are then prone to higher abrasion. The bending of the staves due to thermal stress can be significantly reduced by application of vertical slicing on the ribs. The slicing is shown in Figure 4. In the past, different wear protection methods for the copper staves have been tested. SiC casting has been applied to the hot face but the lifetime was extremely limited. SiC inserts installed in the grooves of the copper staves and protruding about $30 \mathrm{~mm}$ out of the stave surface have shown to delay the wear process. Unfortunately due to thermal stress and chemical attack, the lifetime of the inserts was limited and mostly did not exceed about three years.

In an attempt to provide wear protection over a longer time period, new solutions for the protection of the stave hot face have been developed. The aim of the new solutions is to combine the optimum protection of the blast furnace shell given by the copper stave technology with the improved wear protection inherent to cast iron and steel.

The improved wear protection for bosh and belly staves is shown in Figure 5 . Cast iron blocs and steel blades will be inserted in the grooves of the hot face of the staves to be installed in the bosh and belly area. The protruding cast iron blocs will act as stone boxes where the burden materials can deposit so that the moving burden will slide over this stagnant material and not directly over the stave surface. The accretion layer will also be stabilized by the protruding blocs. The voidage found below the protruding blocs will increase the permeability directly at the wall and thus facilitate the gas flow at the wall. The grooves in between the blocks will be protected against wear by steel blades. The blades which are loosely inserted into the grooves will expand when heating up and then be pressed against the ribs of the stave so that the heat transfer between the blade and the stave is optimal.

\footnotetext{
* Technical contribution to the $44^{\text {th }}$ Ironmaking and Raw Materials Seminar, $15^{\text {rd }}$ Brazilian Symposium on Iron Ore and $2^{\text {nd }}$ Brazilian Symposium on Agglomeration of Iron Ore, September $15^{\text {th }}$ to $18^{\text {th }}$, 2014, Belo Horizonte, MG, Brazil.
} 
Steel blades are also installed as protection on the top surface of the staves and in between two staves in order to avoid abrasion by material flow in the gap in between two staves.

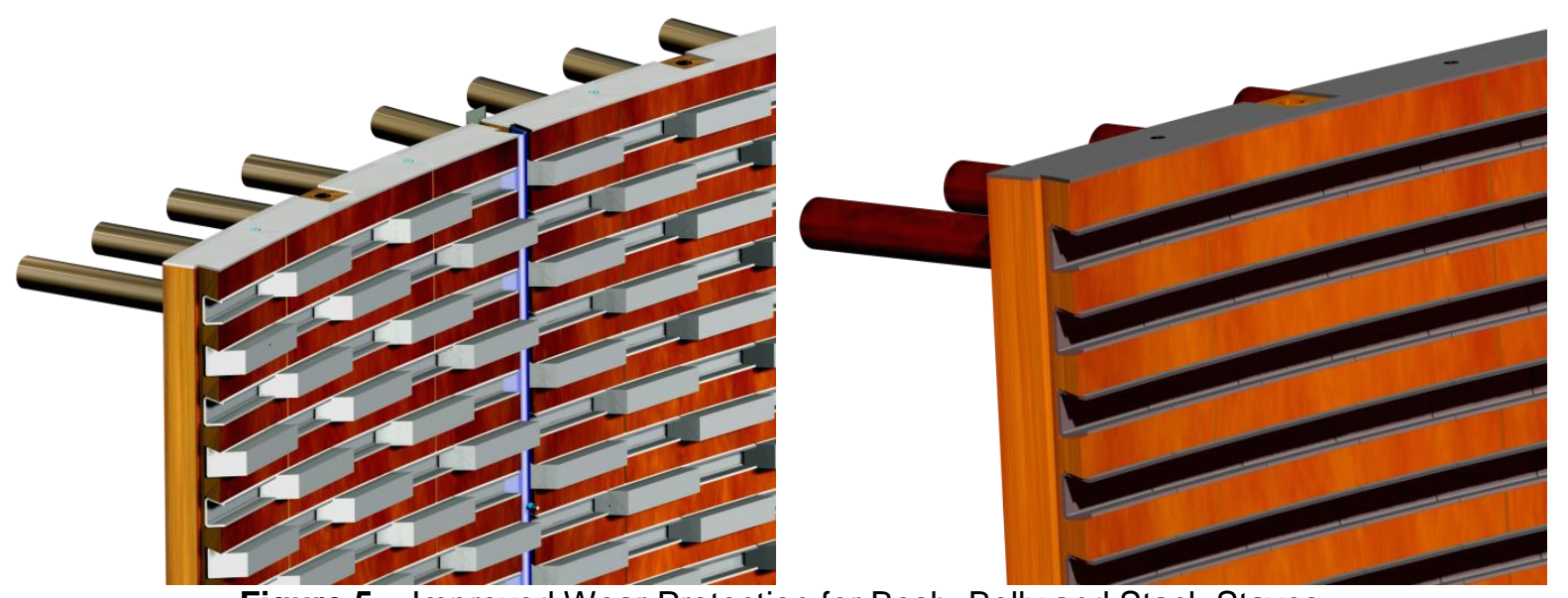

Figure 5. : Improved Wear Protection for Bosh, Belly and Stack Staves

For the staves installed in the lower shaft region steel blades will be inserted into the grooves (see Figure 5). Due to the divergent downward conical shape of the shaft the normal forces of the material on the wall are much lower so that the protection of the rips by steel blades is sufficient.

Experiences made with flow simulations on a cold blast furnace model showed that the build-up of a stagnant material zone in front of the staves located in the zone of the bosh and the belly where the highest wear is found can be positively influenced by a nose protruding from the stave surface inside the blast furnace. In order to achieve an acceptable lifetime of a protruding nose suitable cooling as well as wear protection is required. The protruding nose is thus subdivided into two main parts, a copper body responsible for the cooling and a removable wear protection made of steel. Figure 6 shows the removable wear protection installed in a copper stave.
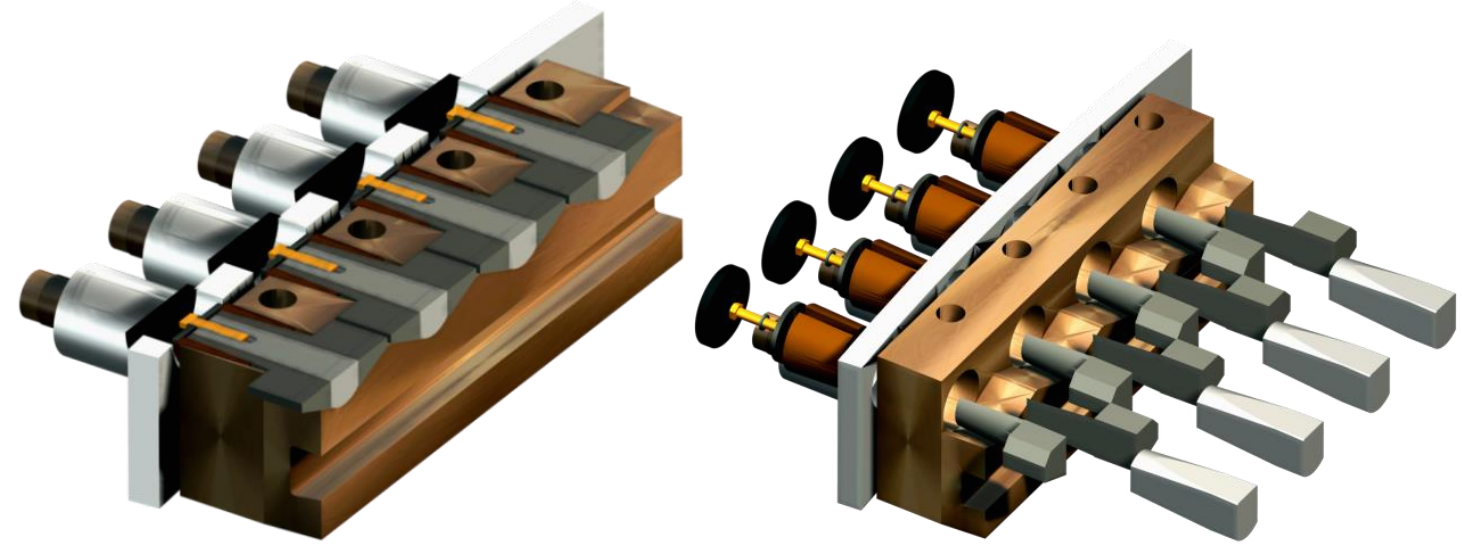

Figure 6. : Removable wear protection

The copper nose is part of the stave body. The removable wear protection consists of three pieces that are inserted through a hole drilled in the stave body in between two cooling channels. A socket with a flanged cover gives access to the replaceable parts through the blast furnace shell. The wear protection part is in contact with the copper nose below so that an optimum cooling of the steel parts is guaranteed. If the wear

\footnotetext{
* Technical contribution to the 44 Ironmaking and Raw Materials Seminar, $15^{\text {rd }}$ Brazilian Symposium on Iron Ore and $2^{\text {nd }}$ Brazilian Symposium on Agglomeration of Iron Ore, September $15^{\text {th }}$ to $18^{\text {th }}$, 2014, Belo Horizonte, MG, Brazil.
} 
protection part sees some wear after a certain time of operation it can easily be replaced during a blast furnace shut-down.

\section{CONCLUSION}

Copper staves have shown their ability to handle the solicitations resulting from operation under changing conditions while achieving higher productivities. They effectively protect the blast furnace shell by insulating it against the high temperature process inside the blast furnace in order to achieve long blast furnace lifetimes. Campaign lifetimes of up to 20 years have shown to be realistic and even some operators have been able to use the same copper staves for a second campaign. The long lifetime is made possible by the basic working principle of copper staves; the build-up of an accretion layer insulating the stave's hot face, thus reducing the heat losses and protecting against wear.

The premature wear experiences observed at some blast furnaces can be explained by a combination of two major factors: a non optimum inner profile and major adverse operation conditions during longer time intervals. The mechanisms leading to this wear have been identified and solutions helping to avoid these adverse operation conditions have been shown. These conditions can be detected at an early stage, first by key-indicators (skin flow temperature, stave body temperature, heat load distribution) and secondly by regular or/and continuous thickness measurements installed on the copper staves, enabling adequate counter-measures. The Bell Less Top and the BFXpert system provide valuable support in optimizing the operation conditions. The new advanced stave design promoting and stabilizing a protective accretion layer in bosh and belly helps to cope with high heat loads and to resist against premature wear. This is achieved by a harder hot face, the creating of a stagnant layer 'stone-box effect' on the hot face as well as the installation of wear resistant elements exchangeable from the outside during planned shut-downs.

In summary it can be concluded that cooling systems based on copper staves are still to be considered as the best basis for achieving long campaign lifetimes under high productivity operation.

\section{REFERENCES}

1 Helenbrook RG, Roy PF, Hille H. Correlation of Experimental Data with Analytical Predictions for Blast Furnace Copper Staves, Association of Iron and Steel Engineers, 1998

2 Schauer C, Filatov S, Fedotov S, Kitchenko V, Kanevskij LA, Stalinsky D, Scoromnyi A. Application of copper staves to an evaporative cooling system of a Russian blast furnace, stahl und eisen 128 (2008) Nr.11

3 Tockert P, Thirion C, Lonardi E, Thillen G, Goffin R, Hausemer L. New Developments in Bell-less Top $\AA$ Charging Technology of Blast Furnaces, AISTech 2009 Proceedings Volume I 413-421.

4 Berdusco D, Hartig, Thillen G, Lonardi E, Hausemer L. The new BLT® High Performance Chute Transmission Gearbox-results of the first 18 months of operation at Rogesa's BF5, AISTech 2012 Proceedings - pp 385

5 Simoes JP, Tockert P, Bermes P, Odicino G, Morelli C, Hansen F, Goedert P, Hausemer L. BFXpert ${ }^{\mathrm{TM}}$ - Paul Wurth's integrated blast furnace level 2 system for best practice blast furnace operation, METEC InSteelCon, 2011.

\footnotetext{
* Technical contribution to the $44^{\text {th }}$ Ironmaking and Raw Materials Seminar, $15^{\text {rd }}$ Brazilian Symposium on Iron Ore and $2^{\text {nd }}$ Brazilian Symposium on Agglomeration of Iron Ore, September $15^{\text {th }}$ to $18^{\text {th }}$, 2014, Belo Horizonte, MG, Brazil.
} 